\title{
Kidney Vascular Disorder
}

National Cancer Institute

\section{Source}

National Cancer Institute. Kidney Vascular Disorder. NCI Thesaurus. Code C35338.

A kidney disorder that results from the damage of the renal arteries or veins. It may lead to renal dysfunction and/or hypertension. 